\title{
Geoscience Fieldwork in the Age of COVID-19 and Beyond: Commentary on the Development of a Virtual Geological Field Trip to Whitefish Falls, Ontario, Canada
}

\author{
Alexander L. Peace* * Jeremy J. Gabriel (1) and Carolyn Eyles \\ School of Earth, Environment and Society, McMaster University, Hamilton, ON L8S3L8, Canada; \\ gabriej@@mcmaster.ca (J.J.G.); eylesc@mcmaster.ca (C.E.) \\ * Correspondence: peacea2@mcmaster.ca
}

check for

updates

Citation: Peace, A.L.; Gabriel, J.J.; Eyles, C. Geoscience Fieldwork in the Age of COVID-19 and Beyond:

Commentary on the Development of a Virtual Geological Field Trip to Whitefish Falls, Ontario, Canada. Geosciences 2021, 11, 489. https:// doi.org/10.3390/geosciences11120489

Academic Editors: Olivier Lacombe and Jesus Martinez-Frias

Received: 24 September 2021 Accepted: 26 November 2021 Published: 30 November 2021

Publisher's Note: MDPI stays neutral with regard to jurisdictional claims in published maps and institutional affiliations.

Copyright: (c) 2021 by the authors. Licensee MDPI, Basel, Switzerland. This article is an open access article distributed under the terms and conditions of the Creative Commons Attribution (CC BY) license (https:/ / creativecommons.org/licenses/by/ $4.0 /)$.

\begin{abstract}
In response to the COVID-19 pandemic and resultant cancelation of geoscience fieldwork, as well as outstanding accessibility issues inherent in conducting fieldwork, we developed a virtual geological fieldtrip (VFT) to the Huronian age deposits in the Whitefish Falls area, Ontario, Canada. This region is a geologically significant site in which many Ontario universities conduct undergraduate teaching due to the high-quality exposures. In this contribution, we describe and comment on the development of this openly available resource, the motivations in doing so, the challenges faced, its pedagogical impact and relevance, as well as provide suggestions to others in the development of such resources. Our multimedia VFT combines $360^{\circ}$ imagery, georeferenced data on integrated maps, and multi-scale imagery (aerial/drone, outcrop, and thin section images). The VFT was built using the Esri Storymaps platform, and thus offers us the opportunity to review the effectiveness of building such resources using this medium, as well as our approach to doing so. We conclude that the Esri Storymaps platform provides a sound medium for the dissemination of multimedia VFTs, but that some aspects of in-person fieldwork remain hard to replicate. Most notably, this affects "hands on experience" and specific activities such as geological mapping. In addition, while VFTs alleviate some accessibility barriers to geoscience fieldwork, substantial barriers remain that should remain the focus of both pedagogical and geoscience work.
\end{abstract}

Keywords: geological fieldwork; virtual field trips; geoscience education

\section{Introduction: Project Rationale, Aims and Motivations}

Field trips and fieldwork have long been part of both the graduate and undergraduate curriculum in the Earth and environmental sciences [1,2]. Indeed, such experiences are seen as an important training ground where crucial geoscientific skills and information are disseminated [3]. This may, in part, reflect the fact that for many geoscience researchers, including the authors of this paper [4-6], fieldwork represents the means by which a large proportion of their primary data is acquired. The effectiveness of field teaching as a pedagogical tool has been shown to be substantial in the literature [7-10]. For example, Elkins \& Elkins [11] conducted a study demonstrating that student participation in an intensive 9-week field-based course produced a statistically significant improvement in geoscience concept knowledge. The effectiveness of field-based education has been shown across many regions [8,12], and its value to student development is clear. In addition, undergraduate field work is usually considered to be one of the highlights of a geoscience curriculum [13].

At McMaster University, as with many other universities [13] with an undergraduatelevel geoscience program, a large proportion of undergraduate field teaching occurs during dedicated field courses, for example, the level-3 "Field Camp", as well as other courses in lower undergraduate levels. However, due to the COVID-19 pandemic, this course, and other undergraduate field-based courses, were canceled in 2020, and it was unclear 
when an in-person delivery would be possible. Field Camp is a core course in the Earth and Environmental Sciences program at McMaster University, but it is also taken by many students from other programs such as those in the Integrated Science (iSci) program, and is also required for professional registration as a geoscientist in the province of Ontario (P.Geo). The cancelation of Field Camp thus presented a substantial challenge to the delivery of a "complete" undergraduate program, that would equip students with the skills and qualifications for their future endeavours.

In addition to the COVID-19 cancelation of fieldwork, the issue of accessibility and inclusivity in fieldwork has been pertinent since well before the pandemic [14-17]. As with many fields, accessibility and inclusivity in the geosciences represents an ongoing challenge [18-22]. Indeed, geoscience fieldwork has been described as having a "culture of exclusion" [23]. In addition, particular groups may experience safety concerns during field-related activities and travel [24]. This is particularly pertinent when it relates to fieldwork where many barriers may exist that prevent a student from fully participating in the educational experience, with implications beyond their university education including limitations of career opportunities [19]. Such barriers include, but are by no means limited to, physical and mental health issues [14,25], financial costs, and time commitments, as demonstrated through interviews with students from underrepresented groups [26].

As educators, it is therefore our duty to maximise accessibility and strive to remove these barriers. VFTs provide a means to facilitate participation of marginalized students, who may have otherwise been excluded from fieldwork (such as Field Camp), to undertake a comparable experience. The reason for this is because VFTs do not exclude participation of students with social, cultural, physical and/or mental health issues. In addition, VFTs have a substantially lower participation cost, in our case, $\$ 0$ for students. For example, a regular iteration of Field Camp costs approximately $\$ 700$ per person, plus expenses for food, equipment, and lost earnings from other employment. A realistic estimate of the full cost of participation in Field Camp at McMaster University is likely $>\$ 1000$. The financial burden of fieldwork has been recognized as a substantial barrier to participation [27]. Whilst we are not suggesting that our VFT will represent a full replacement for Field Camp, it may be able to reduce the time and financial costs, and thus make progress towards alleviating some of the above issues. Indeed, the COVID-19 pandemic has been claimed by previous workers to represent an opportunity to address outstanding geoscience fieldwork accessibility challenges associated with geoscience fieldwork [28]. The concept of a VFT is not a new one however, and well before the COVID-19 pandemic, VFTs for specific educational and outreach purposes were made available (e.g., petroleum geology [29]).

To address the educational requirement gap created by both the COVID-19 situation and ongoing accessibility challenges, our team created a VFT to Whitefish Falls, Ontario to replicate a physical Field Camp. The final VFT can be found here on the Esri Storymaps platform: https://storymaps.arcgis.com/stories/9cac859fac964837bc662492287ae8f0 (accessed on 25 November 2021).

The aims of creating our VFT were as follows:

(1) To provide a field experience when a physical trip is not possible (e.g., the COVID-19 situation), and also for future students who may not be able to undertake fieldwork due to accessibility barriers;

(2) To supplement future physical trips by providing background context to increase effectiveness of the physical trip.

The intended use of our VFT is to facilitate students to progress through the VFT independently, be exposed to the same rock formations, and thus engage in a comparable educational journey they would have experienced in the field. The concept of VFTs is not a recent development, and in fact, they have been used as a pedagogical tool for several decades [30]. In addition, the use of digital technology in the field has been an ongoing area of development for some time [31,32]. Nonetheless, the COVID-19 situation brought VFTs to a more widespread and mainstream educational standpoint. This is reflected in both the scientific and geoscience education literature where an influx of recent 
works is apparent $[1,2,33-36]$. In addition, organizations such as the National Association of Geoscience Teachers (NAGT) have built spaces for the compilation of "remote field experiences" emphasizing the growing importance of this topic [37].

In this contribution, we describe the development of our openly available VFT resource to the Whitefish Falls area of Ontario, Canada, the motivations in doing so, the challenges faced, its pedagogical impact and relevance, as well as provide suggestions to others in the development of such resources. The information in this commentary is intended to supplement the VFT.

\section{Development of the Whitefish Falls VFT}

\subsection{Logistical Considerations}

During a typical in-person iteration of Field Camp, 30-40 students spend $~ 7$ days at Whitefish Falls, Ontario, where they learn to make geological observations, and acquire data and map their results. Here, they apply and build upon the skills and knowledge gained in the classroom by applying them in a practical setting. Geoscience is a practical, hands-on discipline, with a focus on making real-world observations [8,12]. Remote learning, therefore, presents challenges to the delivery of a high-quality geoscience education. Specifically, students can experience difficulties in comprehending geoscience concepts through remote or virtual learning, and instructors can experience difficulties in designing activities that achieve the desired learning outcomes. As such, creating adequate and inclusive resources is challenging. Prior to the creation of our VFT, there were no open resources for the intended study area to deliver this content. This was particularly pertinent and relevant, as many Ontario-based universities also use the Whitefish Falls location for teaching.

One of the first challenges in building our VFT was obtaining support and funding for the project. This support was crucial to the success of the project, as fieldwork is a costly activity and the expenses associated with the development of pedagogical materials do not align neatly with many traditional funding avenues, which are often largely geared towards research activities. Our project found support within the open access movement (see "Acknowledgements" and "Funding" for more details). A further note here is the fact that conducting fieldwork following COVID-19 protocols was found to be more expensive as participants (A.L.P. and J.J.G.) were prohibited from sharing transport and accommodation. Based on our experiences, our suggestion to future VFT developers is to seek funding from outside of traditional research channels such as research councils. This is not to say that these avenues do not offer funding opportunities for VFT development, but the authors of this work found more success in obtaining funding through the organizations noted in the Funding section of this manuscript.

\subsection{Data Types, Materials, and Resources}

Once project funding and support were obtained, the next challenge was to conduct fieldwork to obtain the resources to develop the VFT (e.g., data, photos, observations, etc.). The following section describes the integration of multiple media types into our VFT and the reasons for doing so. In addition to the limitations placed on undergraduate teaching due to the COVID-19 pandemic, restrictions were also placed on other university travel activities due to both internal and external policies that included fieldwork. Although it was eventually possible for the project team to conduct fieldwork, this aspect highlighted the importance of having materials available for construction of the VFT before they are needed. Amongst our colleagues, data and materials previously collected from the mapping area greatly facilitated VFT development prior to fieldwork permissions being granted. As such, we were able to begin VFT development before fieldwork began and offer an encouraging note for geoscience researchers and educators who may not realize how much content they already have through their colleagues.

In the field, the following data types were obtained and eventually integrated into the VFT: (1) digital photos, (2) digital $360^{\circ}$ images, (3) structural orientation data, (4) other 
field-based observations, and (5) rock sample acquisition. These data were amalgamated alongside data already held by the authors and colleagues that included: (1) further digital photographs, (2) regional geoscientific knowledge, (3) aerial photography and digital elevation data (DEM) from a previous drone survey of part of the area. Upon return from the field, the above materials and data were supplemented by thin section preparation followed by microphotograph acquisition.

In designing our VFTs, and specifically considering the media types it would contain, we drew heavily on aspects highlighted in previous work as contributing to successful implementation of VFTs. One such aspect was the use of $360^{\circ}$ and 3D materials [38,39]. As such, we include abundant $360^{\circ}$ imagery in our VFT. The importance of 3D visualization and penetrative thinking skills in the literature is noted [40]. The incorporation of observations at multiple scales is another important aspect highlighted in previous work [41]. Indeed, a multi-scale approach is a central aspect in some previous VFTs [41] and some work focuses on the development of virtual microscope environments [42]. In fact, multiscale observations are potentially more possible in VFTs than regular in-person fieldwork, because it allows the students to focus on pertinent details without being overwhelmed by the larger scale processes, geometries and other aspects. This may represent one of the few areas in which VFTs truly exceed regular in-person fieldwork. However, we are aware of some geoscience educators who combine their field teaching with other activities that facilitate a more multiscale approach, so the latter statement may not be universally true. To enable multi-scale observations in our VFT, we sought to include regional scale observations ( $\mathrm{km}$ scale), as well as outcrop scale (m scale), hand specimen (cm scale), and thin section scale ( $<\mathrm{mm}$ scale) observations. The purpose of this was to allow students to consider how geologic processes at different scales affect and link to one another.

\subsection{Choice of Dissemination Medium}

A range of dissemination media have been utilized to deliver VFTs and other remote educational experiences including, but by no means limited to: webpage-based; Google Earth [1,43]; and Esri StoryMaps [38]. In addition, some workers are actively developing their own platforms for this purpose, including "synthetic virtual worlds" [44] and other game-like virtual environments [45-47]. Each of these platforms comes with its own pros and cons and some media are likely more suitable for certain VFTs than others.

We carefully considered the applicability of each of these platforms, but ultimately chose the Esri StoryMaps platform due to its ability to easily integrate maps containing geographical data into a web-based format. The applicability of Esri StoryMaps to this purpose has been documented in the literature, where it was found to be an "effective teaching tool in science education" [38]. The ArcGIS online tools have been shown in previous work to be useful for the development of VFTs [48], and the StoryMaps aspect in particular has been found to be "user-friendly, interactive, and engaging" [49]. Strachan and Mitchell (2014) [49] did note a number of barriers to the implementation of Esri StoryMaps as a medium for educational resources, such as access to adequate technological resources. In addition, the creation of anything more than basic maps on the platform involves integration with more advanced aspects of geographical information systems (GIS). Nonetheless, Cope et al. (2018) [38] found that participants were positive about the ESRI StoryMaps as a teaching tool.

\section{Discussion: The Future of In-Person and Virtual Fieldwork}

\subsection{The Necessity of Fieldwork in an Increasingly Virtual World}

For several years, an ongoing discussion around the necessity of fieldwork in the modern-day geoscience curriculum has been continuing amongst the geoscientific education community $[10,50,51]$, and the old adage that "the best geologist is the one who has seen the most rocks" is often widely quoted when discussing this topic [52]. The COVID-19 pandemic, and resultant cancelation of fieldwork, has highlighted the importance of this discussion that pre-dated the COVID-19 pandemic. Indeed, the educational value of these 
experiences has been questioned more than ever during the pandemic. The debate centers around whether or not fieldwork still provides a worthwhile educational experience, despite the accessibility and inclusivity challenges.

The value of Earth and Environmental science fieldwork has been repeatedly well documented in the literature. For example, a study presented at the Geological Society of America (GSA) annual meetings in 2010 and 2011 found that $89.5 \%$ of respondents $(n=172)$ indicated that fieldwork should be an integral and required part of undergraduate education [10]. In a separate study on the effectiveness of 3D outcrop models, it was found that only $2 \%$ of participants felt that virtual outcrops could potentially replace in-field teaching, although many positive aspects were noted [39]. From these works, it is clear that in-person geological fieldwork is perceived as a necessity in the undergraduate curriculum.

Through our development of the Whitefish Falls VFT, it has become even more apparent that aspects of in-person fieldwork are near-impossible to fully replicate virtually with current technology. Specifically, the hands-on aspects of fieldwork cannot be easily replicated virtually, and we need to both recognize and address this aspect in future developments. However, this raises the question of whether such "hands-on" aspects truly reflect a learning outcome of a fieldtrip or serve more as a "rite of passage" [53].

One such aspect of fieldtrips that is hard to replicate virtually is geological mapping. In our VFT, we addressed this aspect by showing how such maps are constructed using different layers of GIS-based information. However, we recognize that this is in no way the same experience that students would obtain on an in-person fieldtrip. This challenge has been previously noted with specific efforts made to mimic geological mapping in the virtual environment. For example, through exploration of virtual environments created in the computer game Minecraft, some of the 3D elements of geological mapping may be possible [45].

Another aspect of VFTs that currently does not fully replicate in-person fieldwork is testing the ability of students to make decisions. Instead, most VFTs (including our own) guide students through the experience in a linear manner that is unlike real geological fieldwork, where observations at one site are likely to guide a geologist to their next location. We suggest that future VFTs try to build a more decision-based environment rather than the linear progression of trips such as the one we developed. However, at least one study has shown that the lack of direction in fully open-ended virtual experiences made students uncomfortable in their answers, often checking with the instructor to see if what they were doing was correct [9]. These authors suggest a certain level of structure in the VFT to increase student confidence in completing the assigned tasks.

Overall, based on our experiences, both in developing this VFT and as educators generally, it is clear that we must continue to undertake in-person Earth and environmental science fieldwork, but that VFTs may represent an avenue to address some of the challenges of fieldwork, particularly regarding accessibility and inclusivity. Additionally, as it has been noted in previous work, fieldwork must continue to evolve to meet the changing educational goals, workforce needs, and actual learning outcomes of students [10]. Virtual outcrop models may begin to facilitate virtual mapping in the future [39] but, despite the best efforts of the geoscience education community, there is currently no way to fully replicate the experiences gained through geoscience fieldwork. One possible advantage of the use of VFTs over in-person fieldwork is the ability to integrate a wider range of observational scales into VFTs. Specifically, thin sections of key lithologies could be integrated alongside regional-scale data and observations. Additionally, aerial drone photography and videos can provide a bird's eye view of the site, which may reveal structures and contacts that are difficult to distinguish on the ground. This may extend VFT into territory that traditional in-person fieldwork cannot achieve, but this is a relatively minor consolation given the overall limitation of currently available VFTs.

One major use of VFTs may be found through augmenting in-person trips and/or preparing students for their experiences on actual in-person trips. In addition, open access VFTs allow more wide-ranging field experiences (including beyond national boundaries) 
that may not be otherwise available. VFTs may also provide value by opening the world of field geoscience to younger students and members of the public to explore.

\subsection{Future Directions}

Based on their experiences building a hybrid field-based course during COVID-19, Rotzien et al. [13] felt that they were unable to confidently predict how geoscience fieldwork will evolve over the next 5-10 years, and instead offered a number of scenarios. We concur with their findings, largely due to the high number and complexity of variables at play and find their proposed scenarios plausible. Nonetheless, we do feel that, as with all disciplines, the increased use of technology as an educational tool in geoscience is inevitable, and this will likely mean an increase in the delivery of material virtually. This increase in the abundance, and also sophistication of digital materials, will likely include further use of immersive technologies [54,55]. In addition, we note that guidelines for creation of VFTs are beginning to be developed, with a particular focus on learning outcomes [37], which should be integral to future VFTs. Given the above discussion regarding the aspects of in-person fieldwork that cannot be fully replicated virtually, we highlight the need for Earth and environmental science instructors to maintain a field-based component in their curriculum but be more cognitive of accessibility and inclusivity issues. With careful consideration and adaptation in-person fieldwork can be inclusive. In addition, perceptions of virtual fieldwork versus in-person fieldwork should be investigated further, with specific focus on whether the same learning outcomes can be achieved. With regards to the future development of our own VFTs, we intend to continue the improvement of this through the inclusion of the latest advances in the topic, and further digital media, at this location and other geoscientifically significant sites.

\section{Concluding Remarks}

In this commentary, we have described our experiences planning and building a VFT to the Whitefish Falls area of Ontario, Canada. In sharing these experiences, we hope to facilitate a constructive discussion among the Earth and environmental science education community leading to an increase in the availability and quality of virtual field resources. Each field location presents unique educational opportunities and challenges. At the Whitefish Falls field location that formed the focus of this work, abundant, quality exposure of the rocks facilitated the creation of the digital resources outlined herein. Other potential sites for VFT development may not benefit from such quality exposures which could present an additional challenge in developing materials.

We conclude that while VFTs alleviate some accessibility and inclusivity barriers to geoscience fieldwork, substantial obstacles remain, as it is exceedingly challenging to replicate all aspects of fieldwork virtually. We offer the following as concluding remarks on this topic:

- We found that Esri StoryMaps is a good platform for the development of VFTs for several reasons but most notably for its ability to integrate geospatial data on maps into text-based dialogue;

- Throughout work constructing our VFT, we found that integration of multimedia into VFTs is a worthwhile approach, particularly as this facilitates multi-scale observations, which is one of the few areas in which virtual fieldwork can be seen to potentially excel beyond traditional in-person fieldwork;

- A notable, and reoccurring theme encountered during the development of our VFT is that some aspects of in-person fieldwork remain hard to replicate, for example, geological mapping and decision-based learning.

Supplementary Materials: Other that the VFT described in this commentary which is openly available here: https:/ / storymaps.arcgis.com/stories /9cac859fac964837bc662492287ae8f0 (accessed on 25 November 2021) no other Supplementary Materials are provided. 
Author Contributions: Conceptualization, A.L.P., C.E. and J.J.G.; writing-original draft preparation, A.L.P.; writing-review and editing, C.E., J.J.G. and A.L.P. All authors have read and agreed to the published version of the manuscript.

Funding: Funding for the development of this VFT was kindly provided through an Open Educational Resources (OER) create grant to Alex Peace and Carolyn Eyles that was used to fund Jeremy Gabriel's participation in this project, as well as fieldwork. The OER grant was funded in equal amounts by the McMaster University Libraries, the MacPherson Institute and the Office of the Provost. Alexander Peace and Carolyn Eyles acknowledge Natural Sciences and Engineering Research Council (NSERC) Discovery Grants for research program financial support. Alexander Peace and Carolyn Eyles hold other funding associated with VFT development and review from eCampus Ontario, MITACS and Universitas 21 (U21) which enabled the wider development of a group of researchers and educators to work on this topic.

Institutional Review Board Statement: Not applicable.

Informed Consent Statement: Not applicable.

Data Availability Statement: There are no data associated with the article other than those provided in the VFT: https:/ / storymaps.arcgis.com/stories/9cac859fac964837bc662492287ae8f0 (accessed on 25 November 2021).

Acknowledgments: Olga Perkovic and Joanne Kehoe are thanked for their continued support of this project. Rebecca Moumblow and Heidi Daxberger are thanked for providing thin section photographs. Rebecca Lee is thanked for assistance with Esri StoryMaps, and Patrick Deluca is thanked for facilitating access to StoryMaps. Yorgan Pitt is acknowledged for providing drone data. Joe Boyce and Eduard Reinhardt are acknowledged for writing the McMaster University field camp guide to the area that provided a gateway to the geological history outlined herein. Janok Bhattacharya is acknowledged for providing a field photo and corresponding interpretation. Much of the land that this VFT is located on is part of the Whitefish River First Nation who are gratefully acknowledged for providing access to their lands. This manuscript received feedback from 4 anonymous reviewers which greatly improved the quality of this contribution. We would like to thank all the reviewers for their time and effort reviewing our work.

Conflicts of Interest: The authors declare no conflict of interest. The funders had no role in the design of the study; in the collection, analyses, or interpretation of data; in the writing of the manuscript, or in the decision to publish the results.

\section{References}

1. Whitmeyer, S.J.; Dordevic, M. Creating virtual geologic mapping exercises in a changing world. Geosphere 2021, 17, 226-243. [CrossRef]

2. Evelpidou, N.; Karkani, A.; Saitis, G.; Spyrou, E. Virtual field trips as a tool for indirect geomorphological experience: A case study from the southeast part of the Gulf of Corinth, Greece. Geosci. Commun. 2021, 4, 351-360. [CrossRef]

3. King, C. Geoscience education: An overview. Stud. Sci. Educ. 2008, 44, 187-222. [CrossRef]

4. $\quad$ Peace, A.L.; Welford, J.K.; Geng, M.; Sandeman, H.; Gaetz, B.D.; Ryan, S.S. Rift-related magmatism on magma-poor margins: Structural and potential-field analyses of the Mesozoic Notre Dame Bay intrusions, Newfoundland, Canada and their link to North Atlantic Opening. Tectonophysics 2018, 745, 24-45. [CrossRef]

5. Peace, A.L.; Dempsey, E.D.; Schiffer, C.; Welford, J.K.; Ken, J.W.; McCaffrey, K.; Imber, J.; Phethean, J.J.J. Evidence for basement reactivation during the opening of the Labrador Sea from the Makkovik Province, Labrador, Canada: Insights from field data and numerical models. Geosciences 2018, 8, 308. [CrossRef]

6. Gabriel, J.J.; Reinhardt, E.G.; Peros, M.C.; Davidson, D.E.; van Hengstum, P.J.; Beddows, P.A. Palaeoenvironmental evolution of Cenote Aktun Ha (Carwash) on the Yucatan Peninsula, Mexico and its response to Holocene sea-level rise. J. Paleolimnol. 2009, 42, 199-213. [CrossRef]

7. Zhao, J.; LaFemina, P.; Carr, J.; Sajjadi, P.; Wallgrün, J.O.; Klippel, A. Learning in the field: Comparison of desktop, immersive virtual reality, and actual field trips for place-based STEM education. In Proceedings of the 2020 IEEE Conference on Virtual Reality and 3D User Interfaces, Atlanta, GA, USA, 22-26 March 2020; pp. 893-902.

8. Fuller, I.A.N.; Edmondson, S.; France, D.; Higgitt, D.; Ratinen, I. International perspectives on the effectiveness of geography fieldwork for learning. J. Geogr. High. Educ. 2006, 30, 89-101. [CrossRef]

9. Dolphin, G.; Dutchak, A.; Karchewski, B.; Cooper, J. Virtual field experiences in introductory geology: Addressing a capacity problem, but finding a pedagogical one. J. Geosci. Educ. 2019, 67, 114-130. [CrossRef] 
10. Petcovic, H.L.; Stokes, A.; Caulkins, J.L. Geoscientists' perceptions of the value of undergraduate field education. GSA Today 2014, 24, 4-10. [CrossRef]

11. Elkins, J.T.; Elkins, N.M.L. Teaching geology in the field: Significant geoscience concept gains in entirely field-based introductory geology courses. J. Geosci. Educ. 2007, 55, 126-132. [CrossRef]

12. Marques, L.; Praia, J.; Kempa, R. A study of students' perceptions of the organisation and effectiveness of fieldwork in earth sciences education. Res. Sci. Technol. Educ. 2003, 21, 265-278. [CrossRef]

13. Rotzien, J.R.; Sincavage, R.; Pellowski, C.; Gavillot, Y.; Filkorn, H.; Cooper, S.; Shannon, J.; Yildiz, U.; Sawyer, F.; Uzunlar, N. Field-based geoscience education during the COVID-19 pandemic: Planning, execution, outcomes, and forecasts. GSA Today 2021, 31, 4-10. [CrossRef]

14. Carabajal, I.G.; Marshall, A.M.; Atchison, C.L. A synthesis of instructional strategies in geoscience education literature that address barriers to inclusion for students with disabilities. J. Geosci. Educ. 2017, 65, 531-541. [CrossRef]

15. Atchison, C.L.; Marshall, A.M.; Collins, T.D. A multiple case study of inclusive learning communities enabling active participation in geoscience field courses for students with physical disabilities. J. Geosci. Educ. 2019, 67, 472-486. [CrossRef]

16. Kingsbury, C.G.; Sibert, E.C.; Killingback, Z.; Christopher, L. “Nothing about us without us:" The perspectives of autistic geoscientists on inclusive instructional practices in geoscience education. J. Geosci. Educ. 2020, 68, 302-310. [CrossRef]

17. Atchison, C.L.; Libarkin, J.C. Fostering accessibility in geoscience training programs. Eos Trans. Am. Geophys. Union 2013, $94,400$. [CrossRef]

18. Chiarella, D.; Vurro, G. Fieldwork and disability: An overview for an inclusive experience. Geol. Mag. 2020, 157, 1933-1938. [CrossRef]

19. Stokes, A.; Feig, A.D.; Atchison, C.L.; Gilley, B. Making geoscience fieldwork inclusive and accessible for students with disabilities. Geosphere 2019, 15, 1809-1825. [CrossRef]

20. Olcott, A.N.; Downen, M.R. A guide towards intentional inclusivity of LGBTQ+ geoscientists. In Proceedings of the Goldschimdt Conference, Online, 9 July 2021.

21. Olcott, A.; Downen, M. The challenges of fieldwork for LGBTQ+ geoscientists. Eos 2020, 101, 22-24. [CrossRef]

22. Giles, S.; Jackson, C.; Stephen, N. Barriers to fieldwork in undergraduate geoscience degrees. Nat. Rev. Earth Environ. 2020, 1, 77-78. [CrossRef]

23. Arthurs, L.A. Bringing the field to students during COVID-19 and beyond. GSA Today 2021. [CrossRef]

24. Burek, C.V.; Kölbl-Ebert, M. The historical problems of travel for women undertaking geological fieldwork. Geol. Soc. Lond. 2007, 281, 115-122. [CrossRef]

25. Ward, E.G.; O'Connell, K.B.; Race, A.; Alwin, A.; Alwin, A.; Cortijo-Robles, K.; Esparza, D.; Jolley, A.; McDevitt, A.; Patel, M. Affective learning outcomes in the field. Bull. Ecol. Soc. Am. 2021, 102, 1-12. [CrossRef]

26. Haynes, N.A.; Jacobson, S. Barriers and perceptions of natural resource careers by minority students. J. Environ. Educ. 2015, 46, 166-182. [CrossRef]

27. Abeyta, A.; Fernandes, A.M.; Mahon, R.C.; Swanson, T.E. The true cost of field education is a barrier to diversifying geosciences. EarthArXiv 2021. [CrossRef]

28. Aaisyah, D.; Sahari, S.; Shah, A.A.; Qadir, A.; Prasanna, M.V.; Shalaby, R. COVID-19 as an opportunity to make field-based earth sciences and other similar courses easily accessible and affordable. In Environmental Resilience and Transformation in Times of COVID-19; Elsevier: Amsterdam, The Netherlands, 2021; pp. 333-342.

29. McCaffrey, K.J.W.; Hodgetts, D.; Howell, J.; Hunt, D.; Imber, J.; Jones, R.R.; Tomasso, M.; Thurmond, J.; Viseur, S. Virtual fieldtrips for petroleum geoscientists. In Petroleum Geology: From Mature Basins to New Frontiers, Proceedings of the 7th Petroleum Geology Conference, London, UK, 30 March-2 April 2009; The Geological Society: London, UK, 2010; Volume 7, pp. 19-26.

30. Hurst, S.D. Use of "virtual" field trips in teaching introductory geology. Comput. Geosci. 1998, 24, 653-658. [CrossRef]

31. McCaffrey, K.J.W.; Jones, R.R.; Holdsworth, R.E.; Wilson, R.W.; Clegg, P.; Imber, J.; Holliman, N.; Trinks, I. Unlocking the spatial dimension: Digital technologies and the future of geoscience fieldwork. J. Geol. Soc. Lond. 2005, 162, 927-938. [CrossRef]

32. Mead, C.; Buxner, S.; Bruce, G.; Taylor, W.; Semken, S.; Anbar, A.D. Immersive, interactive virtual field trips promote science learning. J. Geosci. Educ. 2019, 67, 131-142. [CrossRef]

33. Lundmark, A.M.; Augland, L.E.; Jørgensen, S.V. Digital fieldwork with field move-How do digital tools influence geoscience students' learning experience in the field? J. Geogr. High. Educ. 2020, 44, 427-440. [CrossRef]

34. Larsen, T.; Tabor, L.; Smith, P. End of the field? Hacking online and hybrid environments for field-based learning in geography education. J. Geog. 2020, 120, 3-11. [CrossRef]

35. Gregory, D.D.; Tomes, H.E.; Panasiuk, S.L.; Andersen, A.J. Building an online field course using digital and physical tools including VR field sites and virtual core logging. J. Geosci. Educ. 2021, 1-16. [CrossRef]

36. Senger, K.; Betlem, P.; Grundvåg, S.-A.; Horota, R.K.; Buckley, S.J.; Smyrak-Sikora, A.; Jochmann, M.M.; Birchall, T.; Janocha, J.; Ogata, K. Teaching with digital geology in the high Arctic: Opportunities and challenges. Geosci. Commun. 2021, 4, 399-420. [CrossRef]

37. NAGT. Designing Remote Field Experiences. Available online: https://nagt.org/nagt/teaching_resources/field/designing_ remote_field_experie.html (accessed on 11 November 2021).

38. Cope, M.P.; Mikhailova, E.A.; Post, C.J.; Schlautman, M.A.; Carbajales-Dale, P. Developing and evaluating an ESRI story map as an educational tool. Nat. Sci. Educ. 2018, 47, 1-9. [CrossRef] 
39. Bond, C.E.; Cawood, A.J. A role for virtual outcrop models in blended learning-Improved 3D thinking and positive perceptions of learning. Geosci. Commun. 2021, 4, 233-244. [CrossRef]

40. Hannula, K.A. Do geology field courses improve penetrative thinking? J. Geosci. Educ. 2019, 67, 143-160. [CrossRef]

41. Marshall, M.S.; Higley, M.C. Multi-scale virtual field experience: Sedimentology and stratigraphy of Grand Ledge, Michigan, USA. Geosci. Commun. 2021, 4, 461-474. [CrossRef]

42. Jeffery, A.J.; Rogers, S.L.; Jeffery, K.L.A.; Hobson, L. A flexible, open, and interactive digital platform to support online and blended experiential learning environments: Thinglink and thin sections. Geosci. Commun. 2021, 4, 95-110. [CrossRef]

43. Bitting, K.S.; McCartney, M.J.; Denning, K.R.; Roberts, J.A. Conceptual learning outcomes of virtual experiential learning: Results of Google Earth exploration in introductory geoscience courses. Res. Sci. Educ. 2018, 48, 533-548. [CrossRef]

44. Saini-Eidukat, B.; Schwert, D.P.; Slator, B.M. Geology explorer: Virtual geologic mapping and interpretation. Comput. Geosci. 2002, 28, 1167-1176. [CrossRef]

45. Rader, E.; Love, R.; Reano, D.; Dousay, T.A.; Wingerter, N. Pandemic minecrafting: An analysis of the perceptions of and lessons learned from a gamified virtual geology field camp. Geosci. Commun. 2021, 4, 475-492. [CrossRef]

46. Argles, T.; Minocha, S.; Burden, D. Virtual field teaching has evolved: Benefits of a 3D gaming environment. Geol. Today 2015, 31, 222-226. [CrossRef]

47. Houghton, J.J.; Lloyd, G.E.; Robinson, A.; Gordon, C.E.; Morgan, D.J. The virtual worlds project: Geological mapping and field skills. Geol. Today 2015, 31, 227-231. [CrossRef]

48. Phantuwongraj, S.; Chenrai, P.; Assawincharoenkij, T. Pilot study using ArcGIS Online to enhance students' learning experience in fieldwork. Geosciences 2021, 11, 357. [CrossRef]

49. Strachan, C.; Mitchell, J. Teachers' perceptions of Esri Story Maps as effective teaching tools. Rev. Int. Geogr. Educ. Online 2014, 4, 195-220.

50. Brodie, M.W. Soapbox-Masters of Mapping? 2013. Available online: https://www.geolsoc.org.uk/Geoscientist/Archive/ August-2013/Soapbox-Masters-of-mapping (accessed on 25 November 2021).

51. Harker, S. Bring back Real Mapping. 2013. Available online: https://www.geolsoc.org.uk/Geoscientist/Archive/November-20 13/Bring-back-real-mapping (accessed on 25 November 2021).

52. Nichols, G.; Baker, S. Field-Based Training: Luxury or Necessity? 2015. Available online: https://www.geoexpro.com/articles/20 15/07 / field-based-training-luxury-or-necessity (accessed on 25 November 2021).

53. Posselt, J.R.; Nuñez, A.-M. Learning in the wild: Fieldwork, gender, and the social construction of disciplinary culture. J. High. Educ. 2021. [CrossRef]

54. Klippel, A.; Zhao, J.; Oprean, D.; Wallgrün, J.O.; Stubbs, C.; La Femina, P.; Jackson, K.L. The value of being there: Toward a science of immersive virtual field trips. Virtual Real. 2020, 24, 753-770. [CrossRef]

55. Bruce, G.; Mead, C.; Taylor, W.; Anbar, A.D. Gamifying virtual exploration of the past 350 million years of vertebrate evolution. In Proceedings of the AGU Fall Meeting, Online, 1-17 December 2020. 